\title{
Lacrimal fossa lesions: a review of I 46 cases in Egypt
}

Mohammed A Eldesouky'

Molham A Elbakary'

Saly Sabik'

Mohamed M Shareef ${ }^{2}$

'Oculoplastic Unit, Ophthalmology Department, Faculty of Medicine, Tanta University, ${ }^{2}$ Pathology Department, Faculty of Medicine, Tanta University, Tanta, Egypt
Correspondence: Molham A Elbakary Faculty of Medicine, Tanta University, Postal no 31527, Tanta, Egypt

Tel +00 20। I 48282205

Fax +00 20403407734

Email melbakary75@yahoo.com
This article was published in the following Dove Press journal:

Clinical Ophthalmology

26 August 2014

Number of times this article has been viewed

Purpose: The incidence and clinical and imaging criteria of different pathological forms of lacrimal fossa lesions in the Delta region of Egypt were studied.

Methods: A retrospective study of patients with lacrimal fossa lesions for the past 10 years was conducted. A total of 146 cases were identified. Their medical records were reviewed for clinical and imaging data (computed tomography scan, magnetic resonance imaging scan, or both). A definitive diagnosis based on pathological examination of biopsies was also reviewed.

Results: Among the patients reviewed, $43.15 \%$ had inflammatory lacrimal gland lesions, $26.71 \%$ had lymphoproliferative lesions, and $21.92 \%$ had epithelial lesions; $8.22 \%$ had rare lesions (5.48\% were dacryops and $2.74 \%$ had hemangioma). The study included $71.92 \%$ benign lesions and $28.08 \%$ malignant lesions, which were distributed between $19.18 \%$ malignant lymphoma and $8.9 \%$ malignant epithelial tumors. According to the pathological origin of the lesions, they may be classified into $78.08 \%$ nonepithelial lesions and $21.92 \%$ epithelial lesions ( $16.44 \%$ epithelial tumors, and $5.48 \%$ dermoid cysts).

Conclusion: Lacrimal fossa lesions show a wide pathological range. Inflammatory lesions are most frequent, followed by lymphoproliferative and epithelial lesions. Analysis of clinical and radiological criteria is helpful in the differential diagnosis of lacrimal gland lesions.

Keywords: lacrimal gland, tumor, clinical and imaging criteria

\section{Introduction}

Lesions of the lacrimal gland and fossa constitute about 5\%-13\% of all orbital masses confirmed by biopsy. ${ }^{1}$ There are four main groups of lacrimal gland lesions: inflammatory, lymphoid, primary epithelial tumors, and metastatic tumors. ${ }^{2}$ Other less common lesions, such as idiopathic orbital inflammation or developmental cysts, may also occur in lacrimal fossa. ${ }^{3}$ The reported incidences and types of lacrimal fossa lesions in literature showed great variations because of differences in sources of clinical data; patients recruited from primary or tertiary ophthalmic centers may have different spectrum of pathologies. They also varied from different geographic areas. ${ }^{4}$ Patient history and clinical features are important in the differential diagnosis of lacrimal gland lesions; however, the clinical findings may vary from patient to patient. Orbital imaging is required to confirm the diagnosis and characteristics of the lesion; however it is frequently difficult to differentiate each specific disease on the basis of imaging characteristics alone because of intrinsic similarities. ${ }^{5,6}$

In this study, different clinical, imaging criteria, and the incidence of different types of lacrimal fossa lesions in patients in the Delta region of Egypt were studied.

\section{Patients and methods}

In this retrospective study of patients presented or referred to the Oculoplastic Unit, Tanta University Eye Hospital for the last 10 years (2004-2013), a total of 146 patients 
with lacrimal fossa lesions were identified. Their medical records were reviewed for clinical data, including age, sex, laterality, presenting symptoms and duration, upper lid fullness, palpable mass, proptosis, globe displacement, limitation of ocular movements, and visual affection. Imaging data (computed tomography [CT] scan, magnetic resonance imaging [MRI] scan, or both) were also collected, including consistency, appearance (ill or well defined), configuration, and calcification or bone changes. Definitive pathological diagnosis based on biopsy examination (including histopathological and immunohistochemistry data) was also reviewed. The study adhered to the principles of the Declaration of Helsinki, and has been approved by the ethical committee of Tanta University Faculty of Medicine.

\section{Results}

The study included 146 patients of lacrimal fossa lesions. The mean age of patients was 40.43 years, $96(65.75 \%)$ females and 50 (34.25\%) males. Sixty-three patients (43.15\%) had inflammatory lacrimal gland lesions, 39 (26.71\%) had lymphoproliferative lesions, and $32(21.92 \%)$ had epithelial lesions, while $12(8.22 \%)$ had miscellaneous rare lesions (5.48\% were dacryops, and $2.74 \%$ had hemangioma). Collectively, the study included 105 (71.92\%) benign lesions and $41(28.08 \%)$ malignant lesions, which were distributed between 28 (19.18\%) malignant lymphoma and $13(8.9 \%)$ malignant epithelial tumors. According to the pathological origin of the lesions, they may be classified into $78.08 \%$ (114 patients) nonepithelial lesions and 21.92\% (32 patients) epithelial lesions (16.44\% epithelial tumors and 5.48\% dermoid cysts) (Table 1, Figure 1).

\section{Inflammatory lesions}

Sixty-three patients (43.15\%) had inflammatory lacrimal gland lesions. Forty-one patients $(65.08 \%)$ had acute dacryoadenitis, seven patients $(11.11 \%)$ had idiopathic orbital inflammatory disease, seven patients (11.11\%) had granulomatous inflammation (six cases of sarcoidosis and one case of tuberculosis), five patients (7.94\%) had Sjogren's syndrome, and three patients $(4.76 \%)$ had Graves' disease. Twenty-four cases of acute dacryoadenitis resolved completely with medical treatment and were not subjected to biopsy. Mean patient age in this category was 34.1 years (range, 6-62 years); 49 patients $(77.78 \%)$ were females and $14(22.22 \%)$ were males. Bilateral lacrimal gland involvement was recorded in $46.03 \%$ (29 patients). Fifty patients $(79.37 \%$ ) presented with acute onset of painful swelling of less than 1 month duration, while $20.63 \%$ (13 patients) had a chronic course with a mean
Table I Different forms of lacrimal fossa lesions in the study

\begin{tabular}{ll}
\hline Diagnosis & Number of patients (\%) \\
\hline Inflammatory lesions & $63(43.15)$ \\
Acute dacryoadenitis & $41(65.08)$ \\
Idiopathic orbital inflammatory disease & $7(11.11)$ \\
Granulomatous inflammation & $7(11.11)$ \\
Sjögren's syndrome & $5(7.94)$ \\
Grave's disease & $3(4.76)$ \\
Lymphoproliferative lesions & $39(26.71)$ \\
Malignant lymphoma & $28(71.79)$ \\
Benign lymphoid hyperplasia & $11(28.21)$ \\
Epithelial lesions & $32(21.92)$ \\
Dermoid cyst & $8(5.48)$ \\
Epithelial tumors & $24(16.44)$ \\
Malignant & $13(54.17)$ \\
Adenoid cystic & $7(53.8)$ \\
Adenocarcinoma & $3(23.1)$ \\
Undifferentiated & $2(15.4)$ \\
Malignant mixed & $1(7.7)$ \\
Benign & $11(45.17)$ \\
Benign mixed & $9(81.8)$ \\
Endothelioma & $1(9.1)$ \\
Myoepithelioma & $\mathrm{I}(9.1)$ \\
Miscellaneous rare lesions & $12(8.22)$ \\
Dacryops & $8(66.7)$ \\
Hemangioma & $4(33.3)$ \\
\hline
\end{tabular}

symptom duration of 10.2 months. CT scan of these patients showed compressed oblong diffuse enlargement of lacrimal gland with noticeable contrast enhancement. In $71.43 \%$ of patients, this enhancement extended behind the lacrimal gland along the adjacent epibulbar plane, evidenced by a partial ring of sclera and Tenon's capsule thickening. Thickening of adjacent muscle (lateral or superior rectus) was detected in $15.87 \%$ of patients (Figure 2 ).

\section{Lymphoproliferative lesions}

Thirty-nine patients (26.71\%) had lymphoproliferative lesions. The mean age of these patients was 51.47 years; $64.1 \%$ (25 patients) were females, and 35.9\% (14 patients) were males. In $30.77 \%$ of patients $(n=12)$, the lesion was bilateral. Twenty-eight cases $(71.79 \%)$ were malignant lymphoma, while eleven (28.21\%) were benign lymphoid hyperplasia. Thirteen patients with malignant lymphoma (46.43\%) had a history of lacrimal gland swelling; ten of them were previously diagnosed as benign lymphoid hyperplasia, and three were diagnosed as idiopathic inflammation which improved with corticosteroid therapy. The presenting symptom in all cases of this group was upper eyelid fullness. Proptosis or globe displacement was detected in $38.46 \%$ of patients $(n=15)$. Pain was present in $7.69 \%$ of patients $(n=3)$. Duration of symptoms ranged between 2 and 12 months (mean, 5.4 months). CT scan of these patients showed oblong diffuse enlargement of the lacrimal gland with contrast 

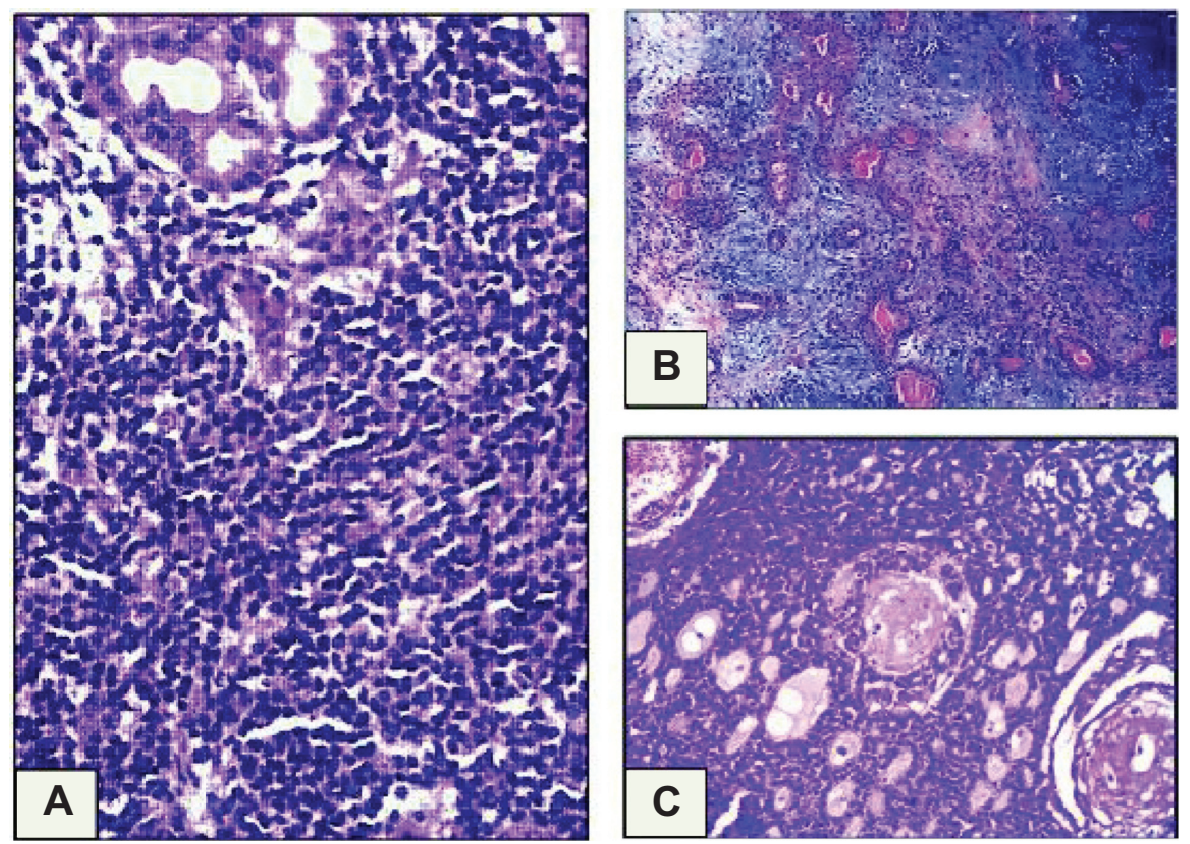

Figure I Hematoxylin and eosin sections of different lacrimal gland lesions.

Notes: (A) Orbital MALT lymphoma with diffuse infiltration by atypical marginal zone lymphocytes and lymphoepithelial lesion. (B) Pleomorphic adenoma showing multiple glandular structures with eosinophilic secretion and surrounding myoepithelial component emanating from the glands, all set within a myxoid stromal background.

(C) Adenoid cystic carcinoma showing a sheet of hyperchromatic basaloid cells with multiple punched out ab-lumenal spaces giving a cribriform pattern.

Abbreviation: MALT, mucosa-associated lymphoid tissue.
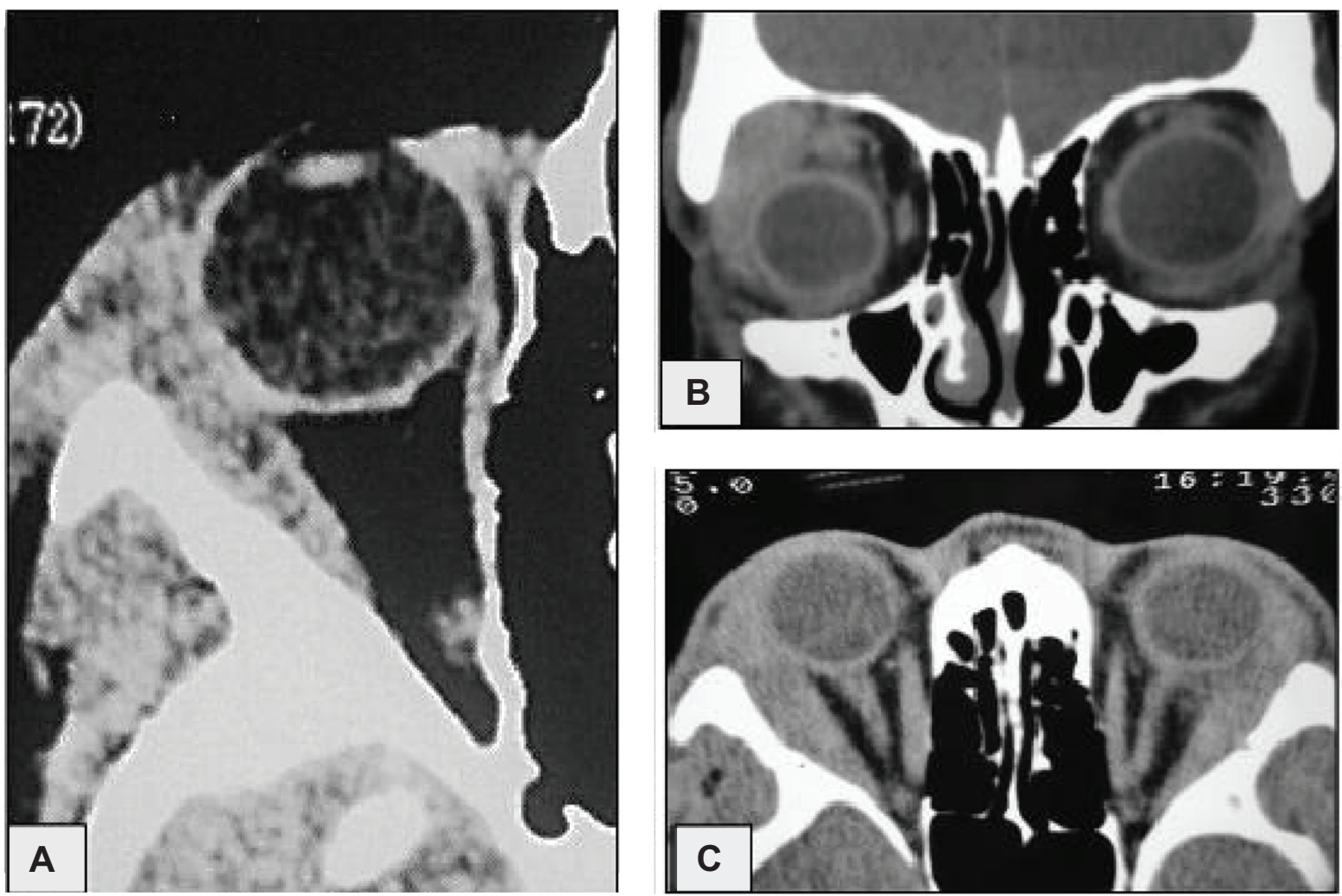

Figure $2 \mathrm{CT}$ scan of inflammatory lesions.

Notes: (A) CT scan of inflammatory lesion showing extended enhancement to the neighboring sclera; (B) CT scan of inflammatory lesion with thickening of the adjacent superior rectus muscle; and (C) CT scan of bilateral inflammatory lesion showing compressed oblong diffuse enlargement of lacrimal glands.

Abbreviation: $\mathrm{CT}$, computed tomography. 

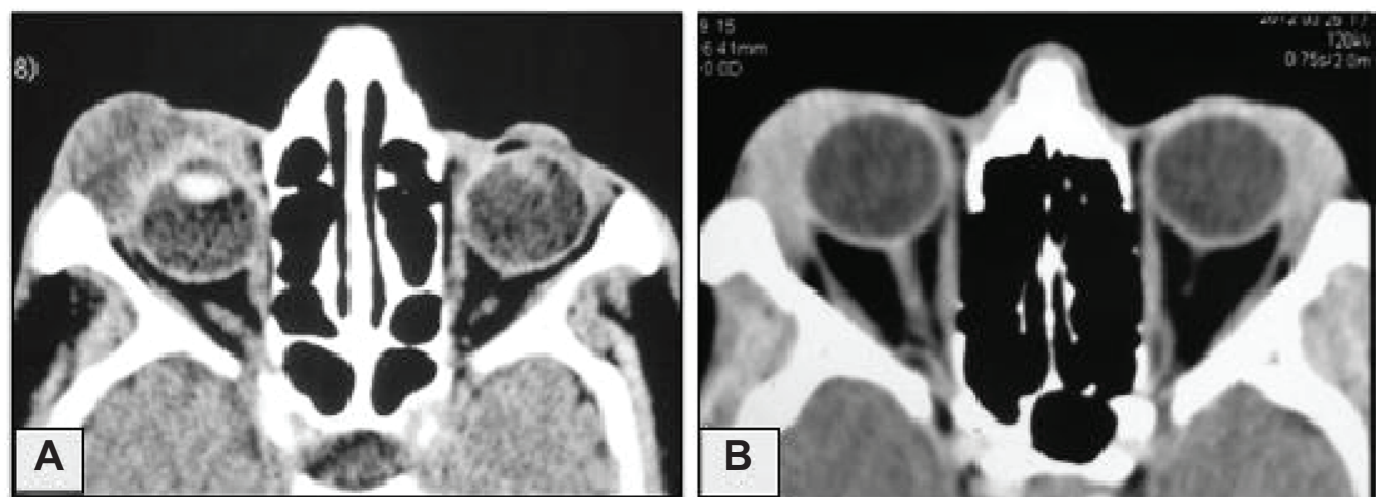

Figure 3 (A) CT scan of pleomorphic adenoma showing rounded well-defined lacrimal gland lesion that did not extend beyond the equator. (B) CT scan of bilateral benign lymphoid hyperplasia showing oblong diffuse enlargement of the lacrimal gland, which extended beyond the equator.

Abbreviation: CT, computed tomography.

enhancement. Absence of muscle thickening differentiated it from inflammatory lesions (Figure 3).

\section{Epithelial lesions}

Thirty-two patients (21.92\%) had lesions of epithelial origin. Eight patients (5.48\%) had dermoid cysts, while 24 patients $(16.44 \%)$ had primary lacrimal gland epithelial tumors. The mean age of patients in the epithelial tumors group was 52.58 years; $58.33 \%$ (14 patients) were male and $41.67 \%$ (ten patients) were female. All patients had unilateral lesion; $54.17 \%$ ( 13 cases) were malignant tumors (seven cases were adenoid cystic carcinoma, three cases were adenocarcinoma not otherwise specified, two were undifferentiated carcinoma, and one case was a malignant mixed tumor) and $45.83 \%$ (eleven patients) had benign epithelial tumors (nine cases were pleomorphic adenoma, one case was endothelioma, and one case was myoepithelioma). In all patients of lacrimal gland malignancy, painful swelling was recorded. Other clinical features included proptosis, globe displacement, and palpable swelling. Duration of symptoms in ten patients ranged between 4 and 11 months (mean, 8.7 months). Three patients had a long history of proptosis and lid swelling of 2-4 years with recent onset pain and exacerbation of proptosis of 2-5 months. CT scan of these patients showed rounded lesions with ill defined edges. Bone erosion was evident in $92.31 \%$ (12 patients), and calcification was detected in $53.85 \%$ (seven patients).

In patients with benign epithelial tumors, the main presenting feature was painless proptosis and globe displacement (72.73\%) and upper lid fullness (54.55\%). A nontender palpable mass was detected in all patients. Duration of symptoms ranged between 8 and 36 months (mean, 24.4 months). CT of these patients showed rounded well-defined lacrimal gland lesions. Bone expansion and fossa formation was detected in $36.64 \%$ (four patients), while calcification was detected in $18.19 \%$ (two patients) (Figures 3-5).

\section{Discussion}

Traditionally, it has been reported that approximately $50 \%$ of lacrimal gland lesions originated from epithelial elements and $50 \%$ are of nonepithelial origin. Among the epithelial tumors, $50 \%$ are pleomorphic adenomas, $25 \%$ are adenoid cystic carcinoma, and the remainder are other types of carcinoma. Of nonepithelial lesions, 50\% are lymphoid tumors and $50 \%$ are inflammatory lesions. ${ }^{7-9}$ There have been many studies that review lacrimal fossa lesions, reporting different incidences reflecting selection bias depending on the institution where the patients were recruited and different geographic locations. ${ }^{4}$ In this study, $43.15 \%$ of patients had inflammatory lesions, $26.71 \%$ had lymphoproliferative lesions, $21.92 \%$ had lesions of epithelial origin, and $8.22 \%$ had miscellaneous rare lesions (5.48\% dacryops, and 2.74\% hemangioma).

Shields et al published a large series of 142 cases of lacrimal gland lesions. They reported $64 \%$ inflammatory lesions, $22 \%$ lesion of epithelial origin (12\% pleomorphic adenoma, $6 \%$ dacryops, and $4 \%$ malignant epithelial tumors). Lastly, $14 \%$ of their cases were lymphoid lesions. ${ }^{1}$ Ohtsuka et al reviewed 244 orbital tumors, of which 86 patients had lacrimal gland lesions. Their study did not include lesions of inflammatory origin. They recorded $58.1 \%$ lymphoid lesions and $41.9 \%$ epithelial lesions $(24.4 \%$ pleomorphic adenoma, $10.6 \%$ dermoid cysts, and $6.9 \%$ malignant epithelial tumors)..$^{10} \mathrm{Ng}$ et al reported $44 \%$ inflammatory lesions, $30 \%$ epithelial lesions (22\% pleomorphic adenoma, $4 \%$ adenoid cystic carcinoma, and $4 \%$ dermoid cyst), and $26 \%$ lymphoid lesions. ${ }^{4}$ These reports, together with our study, show that inflammatory lesions are the most common form 

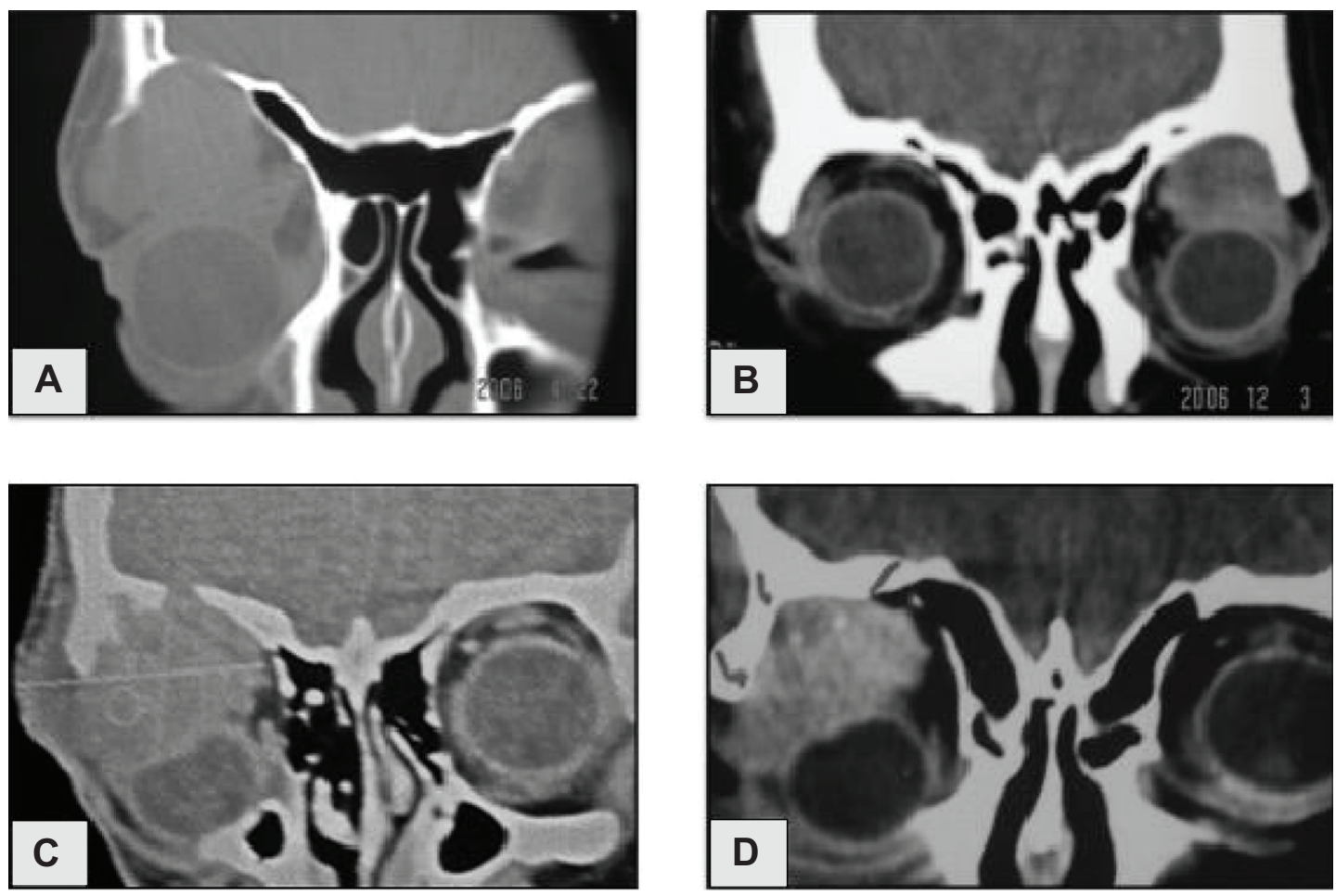

Figure 4 (A) CT scan of adenoid cystic carcinoma on top of pleomorphic adenoma. The expansion of bony fossa is related to the long history of the benign lesion, while the bone erosion is related to malignant transformation. (B) CT scan of pleomorphic adenoma showing expansion of bony fossa. CT scans of adenoid cystic carcinoma showing (C) bone erosion and (D) calcification, respectively.

Abbreviation: $\mathrm{CT}$, computed tomography.

of lacrimal fossa lesions, followed by lymphoproliferative and epithelial lesions, with varying incidences.

Lacrimal gland inflammatory disorders include a wide range of pathological processes. Acute dacryoadenitis could be either bacterial or viral, and is usually unilateral. Patients present with signs of inflammation such as erythema and local tenderness. They tend to respond rapidly to appropriate treatment. ${ }^{11,12}$ Chronic dacryoadenitis may follow acute infection or may be caused by sarcoidosis, Graves' disease,
Wegener's granulomatosis, Sjogren's syndrome, or it may be idiopathic. The lacrimal gland is the second most common site for idiopathic orbital inflammatory disease (IOID). It is difficult to distinguish chronic dacryoadenitis from infiltrative tumors of the lacrimal gland on imaging. CT of these patients usually shows mild to moderate oblong enlargement with moderate to intense enhancement. The IOID may show lateral rectus involvement with scleritis and fluid in the Tenon's capsule. ${ }^{6,11,13}$
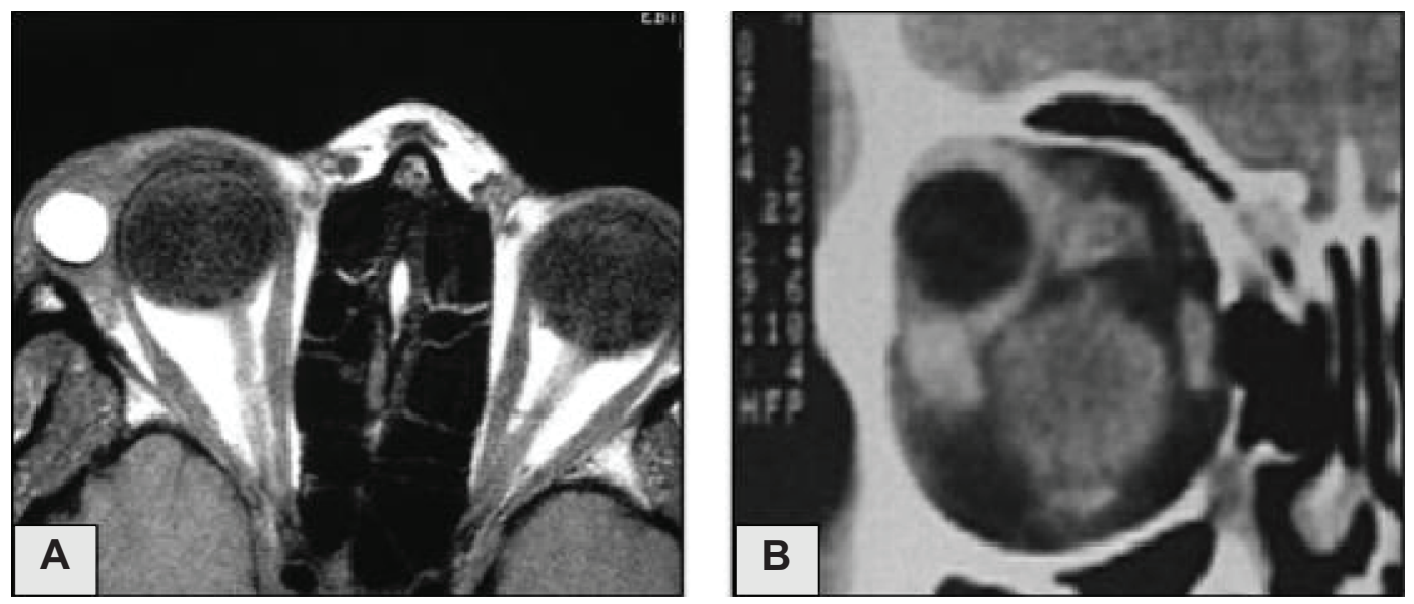

Figure 5 (A) MRI and (B) CT scan of lacrimal fossa dermoid.

Abbreviations: MRI, magnetic resonance imaging; CT, computed tomography. 
Studies of ocular adnexal lymphoid lesions have shown that the most common site for these lesions is the orbit, followed by the conjunctiva and the eyelids. Because many of these studies have not separated lacrimal gland lesions from those of other origins, it is difficult to track the incidence of the former. However, in the largest reported series of ocular lymphomas, about $20 \%$ were lacrimal gland lymphomas. ${ }^{14-16}$ The orbit lacks both a native population of lymphocytes and lymphatic channels and, therefore represents an extralymphatic site. It is now known that mucosal organs contain a part of the specific immune system, termed mucosa-associated lymphoid tissue (MALT). Evidence of a mucosal immune system in the human ocular mucosa has increased over the years. Lymphoid tissue was shown in the conjunctiva, lacrimal gland, and lacrimal drainage system. The accepted presence of lymphoid populations at the ocular surface and adnexa has led to the concept of the eye-associated lymphoid tissue (EALT), a new component of the mucosal immune system of the body. ${ }^{17-21}$

Malignant lymphoma was recorded to be more common than benign lymphoid hyperplasia in many reports. Shields et al reported that $70 \%$ of lacrimal gland lymphoid lesions were malignant. ${ }^{22} \mathrm{~A}$ similar ratio of $68 \%$ was recorded by Ohtsuka et al and 79\% was recorded by Farmer et al. ${ }^{10,17}$ Malignant lymphoma represented $71.79 \%$ of lacrimal gland lymphoid lesions in this series. Radiologically, it is challenging to differentiate a benign nonepithelial tumor from a malignant lymphoma. Inflammatory and lymphoproliferative lesions tend to involve the whole aspect of the lacrimal gland. They appear as diffuse enhanced lesions demonstrating soft tissue characteristics in CT and MRI. ${ }^{23}$ Recently, radiological reports referred to the value of apparent diffusion coefficient (ADC) weighted MR in diagnosis of lacrimal gland lymphoma. It was observed that lymphomas have ADCs significantly lower than those of the majority of other lacrimal lesions. This may be probably related to greater cellularity, high nucleus to cytoplasm ratio, and less extracellular space and therefore less random motion of water. This additional information improves the diagnostic accuracy of MRI with sensitivity and specificity more than $90 \%$, consequently reducing the number of unnecessary biopsies with subsequent implications for patient care. ${ }^{24-26}$

Among study patients, $21.92 \%$ had lesions of epithelial origin: $16.44 \%$ of which were epithelial tumors; $54 \%$ of the epithelial tumors were malignant, while $46 \%$ were benign. Many authors report a similar range of $50 \%$ benign and malignant epithelial lacrimal gland tumors. ${ }^{2,27,28}$ Other reports recorded that benign tumors are in the range of $70 \%$ of epithelial lacrimal gland tumors. ${ }^{1,29,30}$ This variation may arise from the different institutions and referral centers from which the patients were recruited. The mean age of patients with malignant epithelial tumors (55.46 years) was relatively larger than that of patients with benign epithelial tumors (49.18 years). Adenoid cystic carcinoma was the most common form of malignant epithelial tumors (53.84\%); this was also reported by many authors. ${ }^{1,30-32}$ Wright et al reported that patients with adenoid cystic carcinoma tended to be younger than those with adenocarcinoma or malignant mixed tumors, and all patients presenting younger than 30 years of age had adenoid cystic carcinoma. ${ }^{31}$ Two patients with malignant epithelial tumors in this study were younger than 30 years, and both of them had adenoid cystic carcinoma.

Clinically, benign epithelial tumors present as painless, slow-growing tumors in the upper lateral eyelid with proptosis and inferomedial displacement of the globe. On the other hand, pain is an important symptom of lacrimal gland malignancy,

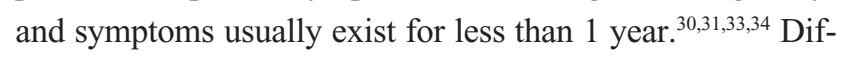
ferentiation between benign and malignant epithelial lacrimal gland tumors should be achieved on a clinical and radiological basis, as pleomorphic adenomas have a high rate of recurrence if tumor cells are dispersed into the adjacent tissues during excision or biopsy. This recurrence has the risk of being malignant. ${ }^{27,34}$ Rose et al proposed a diagnostic plan for diagnosis of persistent lacrimal gland masses, taking into account clinical and radiological criteria. They gave a score of -1 or +1 to each of the following criteria: duration of symptoms (less or more than 10 months), persistent pain (present or absent), welldefined mass in radiology, molding of mass to the globe, tumor calcification, and bone destruction. They stated that a total score of -8 to +2 favors the diagnosis of malignancy, while a score of +3 to +8 is probably a pleomorphic adenoma for total excision without prior biopsy. ${ }^{34}$ On the other hand; fine needle aspiration may provide a great advantage to ophthalmic surgeons who routinely operate in a more conservative fashion. Some reports indicated that fine needle aspiration is a reliable and effective tool in the diagnosis and management of primary epithelial tumors of the lacrimal gland. ${ }^{35}$

In this study, $5.48 \%$ of patients had dermoid cysts. Dermoid and epidermoid lesions are a result of developmental sequestration of ectoderm within the suture lines of orbital bones. They are not true lacrimal gland tumors, but arise from epithelial rests in the lacrimal fossa. They can present at any age; the recorded age range is $10-91$ years. ${ }^{36,37}$

In conclusion, lacrimal fossa lesions show a wide pathological range. Inflammatory lesions are most frequent, followed by lymphoproliferative and epithelial lesions. Malignant lesions are the more common form among lymphoid lesions and represents about half of the epithelial tumors. Analysis of clinical and radiological criteria is helpful 
to achieve a provisional diagnosis, and is crucial when lacrimal gland epithelial tumor is suspected.

\section{Disclosure}

The authors report no conflicts of interest in this work.

\section{References}

1. Shields CL, Shields JA, Eagle RC, Rathmell JP. Clinicopathologic review of 142 cases of lacrimal gland lesions. Ophthalmology. 1989; 96(4):431-435.

2. Font RL, Smith SL, Bryan RG. Malignant epithelial tumors of the lacrimal gland: a clinicopathologic study of 21 cases. Arch Ophthalmol. 1998;116(5):613-616.

3. Balchunas WR, Quencer RM, Byrne SF. Lacrimal gland and fossa masses: evaluation by computed tomography and A-mode echography. Radiology. 1983;149(3):751-758.

4. Ng DS, Chan E, Yau K, Chan CW. Clinicopathological survey of 23 patients with lacrimal fossa lesions in Hong Kong. Int J Ophthalmol. 2011;4(3): 311-313.

5. Gündüz K, Shields CL, Günalp I, Shields JA. Magnetic resonance imaging of unilateral lacrimal gland lesions. Graefes Arch Clin Exp Ophthalmol. 2003;241(11):907-913.

6. Vaidhyanath R, Kirke R, Brown L, Sampath R. Lacrimal fossa lesions: pictorial review of CT and MRI features. Orbit. 2008;27(6):410-418.

7. Reese $\mathrm{AB}$. The treatment of expanding lesions of the orbit with particular regard to those arising in the lacrimal gland. The Seventh Arthur J Bedell Lecture. Am J Ophthalmol. 1956;41:3-11.

8. Tse DT, Neff AG, Onofrey CB. Recent developments in the evaluation and treatment of lacrimal gland tumors. Ophthalmol Clin North Am. 2000;13:663-681.

9. Goder GJ. Tumours of the lacrimal gland. Orbit. 1982;1:91-96.

10. Ohtsuka K, Hashimoto M, Suzuki Y. A review of 244 orbital tumors in Japanese patients during a 21-year period: origins and locations. Jpn J Ophthalmol. 2005;49(1):49-55.

11. Mafee MF. Orbit: Embryology, anatomy, and pathology. In: Som PM, Curtin HD. (eds.) Head and Neck Imaging. 4th ed, Vol. 1. St Louis, MO: Mosby, 2003. p 543-547.

12. Mafee MF, Haik BG. Lacrimal gland and fossa lesions: role of computed tomography. Radiol Clin North Am. 1987;25(4):767-779.

13. Mafee MF, Edward DP, Koeller KK, Dorodi S. Lacrimal gland tumors and simulating lesions. Clinicopathologic and MR imaging features. Radiol Clin North Am. 1999;37(1):219-239, xii.

14. Knowles DM, Jakobiec FA, McNally L, Burke JS. Lymphoid hyperplasia and malignant lymphoma occurring in the ocular adnexa (orbit, conjunctiva, and eyelids): a prospective multiparametric analysis of 108 cases during 1977 to 1987. Hum Pathol. 1990;21(9):959-973.

15. Liesegang TJ. Ocular adnexal lymphoproliferative lesions. Mayo Clin Proc. 1993;68(10):1003-1010.

16. Jakobiec FA, Knowles DM. An overview of ocular adnexal lymphoid tumors. Trans Am Ophthalmol Soc. 1989;87:420-442; discussion $442-444$

17. Farmer JP, Lamba M, Lamba WR, et al. Lymphoproliferative lesions of the lacrimal gland: clinicopathological, immunohistochemical and molecular genetic analysis. Can J Ophthalmol. 2005;40(2):151-160.

Clinical Ophthalmology

\section{Publish your work in this journal}

Clinical Ophthalmology is an international, peer-reviewed journal covering all subspecialties within ophthalmology. Key topics include: Optometry; Visual science; Pharmacology and drug therapy in eye diseases; Basic Sciences; Primary and Secondary eye care; Patient Safety and Quality of Care Improvements. This journal is indexed on Submit your manuscript here: http://www.dovepress.com/clinical-ophthalmology-journal
18. Wieczorek R, Jakobiec FA, Sacks EH, Knowles DM. The immunoarchitecture of the normal human lacrimal gland. Relevancy for understanding pathologic conditions. Ophthalmology. 1988;95(1):100-109.

19. Knop E, Knop N. A functional unit for ocular surface immune defense formed by the lacrimal gland, conjunctiva and lacrimal drainage system. Adv Exp Med Biol. 2002;506(Pt B):835-844.

20. Knop E, Knop N. The role of eye-associated lymphoid tissue in corneal immune protection. J Anat. 2005;206(3):271-285.

21. Knop E, Knop N, Claus P. Local production of secretory IgA in the eye-associated lymphoid tissue (EALT) of the normal human ocular surface. Invest Ophthalmol Vis Sci. 2008;49(6):2322-2329.

22. Shields JA, Shields CL, Scartozzi R. Survey of 1264 patients with orbital tumors and simulating lesions: The 2002 Montgomery Lecture, part 1. Ophthalmology. 2004;111(5):997-1008.

23. Shields JA, Bakewell B, Augsburger JJ, Donoso LA, Bernardino V. Space-occupying orbital masses in children. A review of 250 consecutive biopsies. Ophthalmology. 1986;93(3):379-384.

24. Politi LS, Forghani R, Godi C, et al. Ocular adnexal lymphoma: diffusion-weighted $\mathrm{mr}$ imaging for differential diagnosis and therapeutic monitoring. Radiology. 2010;256(2):565-574.

25. Srinivasan A, Dvorak R, Perni K, Rohrer S, Mukherji SK. Differentiation of benign and malignant pathology in the head and neck using $3 \mathrm{~T}$ apparent diffusion coefficient values: early experience. AJNR Am J Neuroradiol. 2008;29(1):40-44.

26. Elkhamary SM. Lacrimal gland lesions: can addition of diffusionweighted MR imaging improve diagnostic accuracy in characterization? Egypt J Radiol Nuclear Med. 2012;43:165-172.

27. Font RL, Gamel JW. Epithelial tumors of the lacrimal gland: an analysis of 265 cases. In: Jakobiec FA, editor. Ocular and Adnexal Tumors. Birmingham, AL: Aesculapius Publishing, 1978;787-805.

28. Ni C, Kuo PK, Dryja TP. Histopathological classification of 272 primary epithelial tumors of the lacrimal gland. Chin Med J (Engl). 1992;105(6): 481-485.

29. Kennedy RE. An evaluation of 820 orbital cases. Trans Am Ophthalmol Soc. 1984;82:134-157.

30. Snaathorst J, Sewnaik A, Paridaens D, de Krijger RR, van der Meij EH. Primary epithelial tumors of the lacrimal gland; a retrospective analysis of 22 patients. Int J Oral Maxillofac Surg. 2009;38(7):751-775.

31. Wright JE, Rose GE, Garner A. Primary malignant neoplasms of the lacrimal gland. Br J Ophthalmol. 1992;76(7):401-407.

32. Shinder R, Al-Zubidi N, Esmaeli B. Survey of orbital tumors at a comprehensive cancer center in the United States. Head Neck. 2011;33(5): 610-614.

33. Wright JE, Stewart WB, Krohel GB. Clinical presentation and management of lacrimal gland tumours. Br J Ophthalmol. 1979; 63(9):600-606.

34. Rose GE, Wright JE. Pleomorphic adenoma of the lacrimal gland. $\mathrm{Br}$ J Ophthalmol. 1992;76(7):395-400.

35. Sturgis CD, Silverman JF, Kennerdell JS, Raab SS. Fine-needle aspiration for the diagnosis of primary epithelial tumors of the lacrimal gland and ocular adnexa. Diagn Cytopathol. 2001;24:86-89.

36. Chawda SJ, Moseley IF. Computed tomography of orbital dermoids: a 20-year review. Clin Radiol. 1999;54(12):821-825.

37. Smirniotopoulos JG, Chiechi MV. Teratomas, dermoids, and epidermoids of the head and neck. Radiographics. 1995;15(6):1437-1455.

PubMed Central and CAS, and is the official journal of The Society of Clinical Ophthalmology (SCO). The manuscript management system is completely online and includes a very quick and fair peer-review system, which is all easy to use. Visit http://www.dovepress.com/ testimonials.php to read real quotes from published authors. 